\title{
Cutaneous Lymphangioma circumscriptum - dermoscopic features
}

\author{
António Fernandes Massa ${ }^{1}$ \\ Nuno Menezes ${ }^{1}$ \\ Armando Baptista ${ }^{1}$
}

\author{
Ana Isabel Moreira ${ }^{1}$ \\ Eduarda Osório Ferreira ${ }^{1}$
}

Abstract: Lymphangiomas are congenital lymphatic malformations and cutaneous lymphangioma circumscriptum is the most common type. It is clinically characterized by clusters of translucent vesicles and the presence of dermoscopically yellow lacunae surrounded by pale septa, as well as reddish to bluish lacunae. In our case, the recently described hypopyon-like feature manifested, aiding in the sometimes difficult differential diagnosis of cutaneous lymphangioma circumscriptum with vascular lesions, further highlighting the importance of dermoscopy in what can be a diagnostic challenge.

Keywords: Lymphangioma; Dermoscopy; Vascular malformations

Lymphangiomas are congenital lymphatic malformations, accounting for $4 \%$ of all vascular tumours and $25 \%$ of benign vascular growths in children. ${ }^{1}$

The most common type of lymphangioma, cutaneous lymphangioma circumscriptum, is now described as superficial lymphatic malformation (SLM). ${ }^{2}$

It is clinically characterized by clusters of translucent vesicles resembling frog spawn on the skin and its main differential diagnoses are with lymphangiectasis, hemangioma, angiokeratoma, angiosarcoma, metastatic carcinoma to the skin, verrucae, molluscum contagiosum, warts and epidermal nevi. ${ }^{1,3,4,5}$

Multiple dilated lymphatic channels usually located in the superficial dermis characterize it histologically. The condition often extends into the epidermis, which can be acanthotic, and a stromal lymphocytic infiltrate is present. ${ }^{6}$

Dermoscopic features of SLM were first described as two distinct patterns: yellow lacunae surrounded by pale septa without inclusion of blood; and yellow to pink lacunae alternating with dark-red or bluish lacunae, due to the inclusion of blood, mak- ing it a difficult differential diagnosis with haemangioma when a marked content of blood was present. ${ }^{7}$ These findings were well correlated with histologic features. $^{8}$

A 17-year-old male was referred to our outpatient clinic for evaluation of an asymptomatic verrucous-like lesion in his right axillary fold, which he had had since the age of 8 . It had been treated through cryosurgery for clinical suspicion of molluscum contagiosum. Clinical examination showed an irregular plaque involving vesicles with serous and serohematic filling, maximum dimensions of $7 \times 2 \mathrm{~cm}$ and two vesicular satellite lesions, also with serohematic filling (Figure 1).

Dermoscopy showed red and pale areas with hypopyon-like lesions and whitish, yellowish lacunar areas with thin linear vessels (Figure 2).

Histology showed thin walled lymphatic vessels in the reticular and papillary dermis, confirming the diagnosis of superficial lymphatic malformation (Figure 3).

\footnotetext{
Received on 24.04.2014.

Approved by the Advisory Board and accepted for publication on 26.06.2014.

* Work performed at the Department of Dermatology Centro Hospitalar de V.N.Gaia/Espinho, EPE, Vila Nova de Gaia, Portugal. Conflict of interest: None

Financial funding: None

Centro Hospitalar de Vila Nova de Gaia - Espinho, Portugal. 


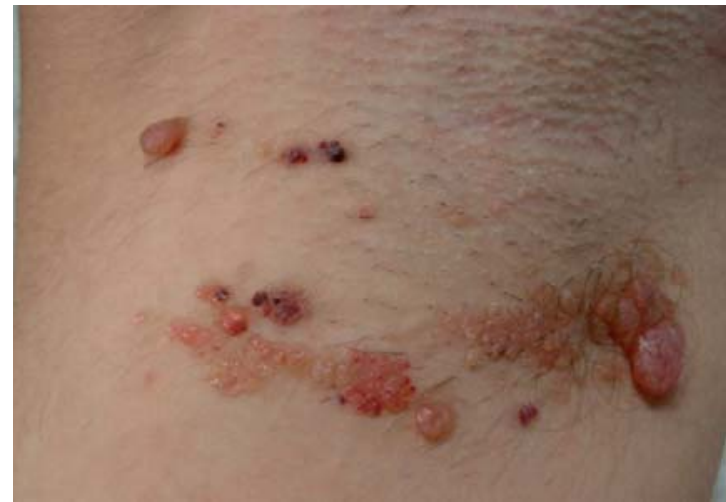

FIGURE 1: Right axillary plaque composed of vesicles with serous and serohematic filling and two vesicular satellite lesions with serohematic filling
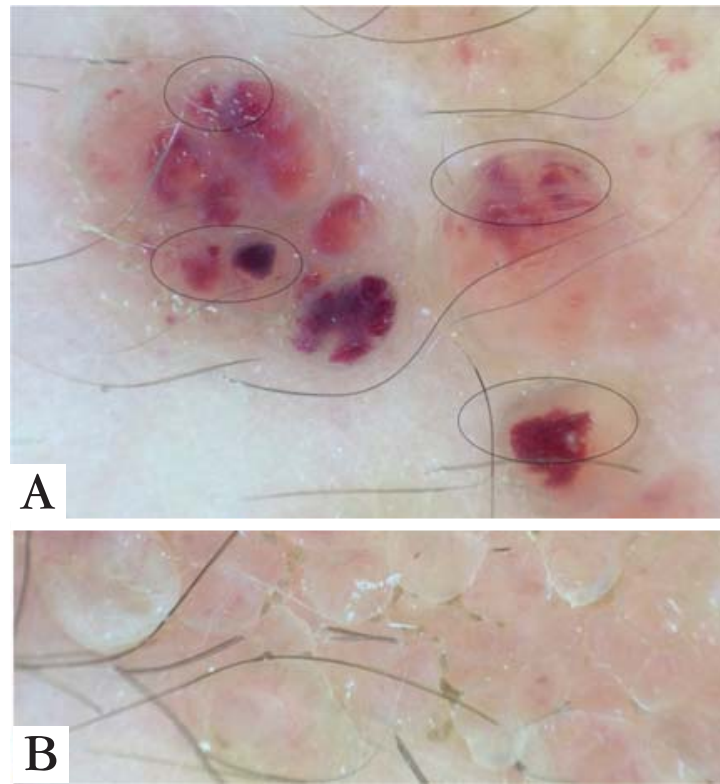

Figure 2: a) Dermoscopy - Red and pale homogenous areas resembling vascular lagoons. In some, a raised surface appeared due to the sedimentation of blood according to their corpuscles density, leading to a color transition from dark to light in some lacunae -Hypopyon-like (circles). b) Dermoscopy - Whitish and yellowish lacunar areas with thin linear vessels

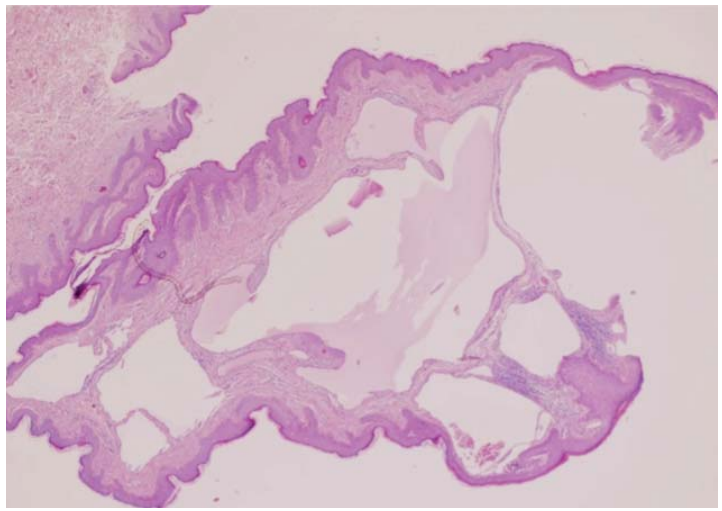

FIGURE 3: Haematoxylin and eosin staining - 10x - Thin walled lymphatic vessels in reticular and papillary dermis

Electrodessication was performed, leading to a good cosmetic result, without recurrence after a 3month follow-up.

Cutaneous lymphangioma is clinically defined by a clustering of vesicles with varying content in blood. In dermoscopy, this features as brownish lacunas limited by pale septa or reddish areas in some lagoons, depending on the blood content. ${ }^{7.9}$

A new pattern has recently been described in addition to the pink diffuse coloration and reddish to violaceous lacunar structures. As sedimentation of blood occurs, its corpuscles aggregate according to their density, with cellular components lying at the bottom and serum at the upper part, leading to a color transition from dark to light in some lacunae, creating a similar effect to that seen on the eye - the hypopyon. ${ }^{10}$

This particular aspect is present in our case, enhancing its reliability as a dermoscopic criterion for the diagnosis.

Although dermoscopy plays a major role in the diagnosis of SLM, histology remains the gold standard for diagnosis and should not be forgotten in the clinical context of an entity with frequent recurrence after treatment and possible differential diagnosis with carcinoma telangiectoides. ${ }^{1}$

\section{ACKNOWLEDGEMENTS}

Acknowledgements to Dr. Olinda Lima for her collaboration in the pathology work and for the histopathological images. 


\section{REFERENCES}

1. Patel GA, Schwartz RA. Cutaneous lymphangioma circumscriptum: frog spawn on the skin. Int J Dermatol. 2009;48:1290-5.

2. James WD, Burger T, Elston D. Andrews' Diseases of the Skin Clinical Dermatology. 10th ed. Saunders Elsevier: United Kingdom; 2011. p.579-82.

3. Drachman D, Rosen L, Sharaf D, Weissmann A. Postmastectomy low-grade angiosarcoma. An unusual case clinically resembling a lymphangioma circumscriptum. Am J Dermatopathol. 1988;10:247-51.

4. Kim JH, Nam TS, Kim SH. Solitary angiokeratoma developed in one area of lymphangioma circumscriptum. J Korean Med Sci. 1988;3:169-70.

5. Terushkin V, Marmon S, Fischer M, Patel RR, Sanchez MR. Verrucous lymphangioma circumscriptum. Dermatol Online J. 2012;18:9.

6. Calonje E, Brenn T, Burger T, Elston D. McKee's Pathology of the Skin: with clinical correlations. 4th ed. Saunders Elsevier: United Kingdom; 2012. p.1743-5.

7. Arpaia N, Cassano N, Vena GA. Dermoscopic features of cutaneous lymphangioma circumscriptum. Dermatol Surg. 2006;32:852-4.

8. Amini S, Kim NH, Zell DS, Oliviero MC, Rabinovitz HS. Dermoscopic-histopathologic correlation of cutaneous lymphangioma circumscriptum. Arch Dermatol. 2008:144:1671-2.

9. Dominguez, V. Dermoscopia de linfangioma circunscrito neviforme. Revista SPDV. 2012; 70:369 -73

10. Gencoglan G, Inanir I, Ermertcan AT. Hypopyon-like features: new dermoscopic criteria in the differential diagnosis of cutaneous lymphangioma circumscriptum and haemangiomas J Eur Acad Dermatol Venereol. 2012;26:1023-5.

\author{
MAILING ADDRESS: \\ António Fernandes Massa \\ R. Conceição Fernandes \\ 4430 Vila Nova de Gaia \\ Portugal \\ E-mail:antoniofmassa@gmail.com
}

How to cite this article: Massa AF, Moreira AI, Menezes N, Osório-Ferreira E, Baptista A. Cutaneous Lymphangioma circumscriptum - dermoscopic features. An Bras Dermatol. 2015;90(2):262-4. 